
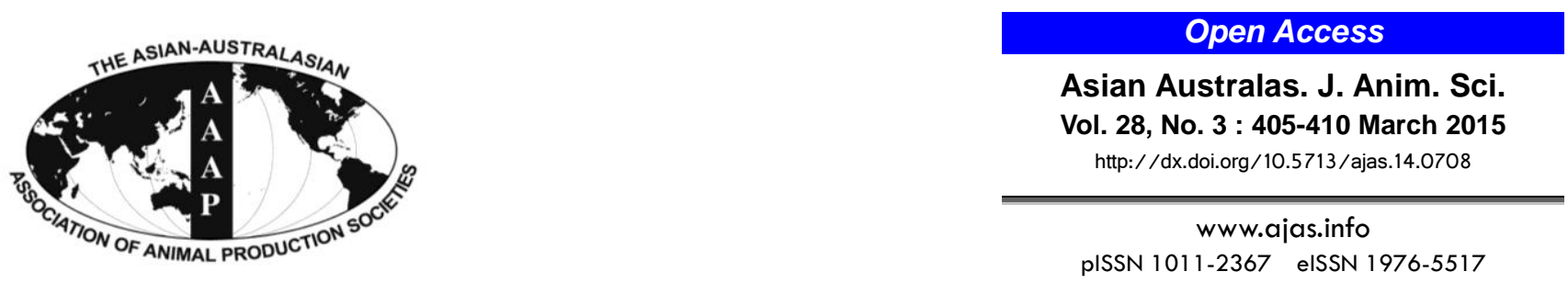

\title{
Evaluation of Antimicrobial Activities of Sequential Spray Applications of Decontamination Treatments on Chicken Carcasses
}

\author{
Hakan Benli ${ }^{1} *$, Marcos X. Sanchez-Plata ${ }^{2}$, Osman Irfan Ilhak ${ }^{3}$, \\ Maryuri T. Núñez De González ${ }^{4}$, and Jimmy T. Keeton \\ Department of Nutrition and Food Science, Texas A\&M University, College Station, TX 77843-2253, USA
}

\begin{abstract}
The objective of this study was to evaluate the effects of sequential applications of $\varepsilon$-polylysine (EPL) or lauramide arginine ethyl ester (LAE) sprays followed by an acidic calcium sulfate (ACS) spray on inoculated chicken carcasses to reduce Salmonella (Salmonella enterica serovars including Salmonella typhimurium and Salmonella enteritidis) contamination during 6 days of storage $\left(4.4^{\circ} \mathrm{C}\right)$. Secondly, reductions of the resident microflora were studied on uninoculated chicken carcasses following the sequential application of the treatments, chilling and 10 days of storage at $4.4^{\circ} \mathrm{C}$. The treatment of Salmonella inoculated carcasses with $300 \mathrm{mg} / \mathrm{L}$ EPL followed by $30 \%$ ACS (EPL300-ACS30) sprays reduced Salmonella counts initially by $1.5 \mathrm{log} \mathrm{cfu} / \mathrm{mL}$ and then by $1.2 \mathrm{log}$ cfu/mL $(\mathrm{p}<0.05)$ following 6 days of storage at $4.4^{\circ} \mathrm{C}$. Likewise, $200 \mathrm{mg} / \mathrm{L} \mathrm{LAE}$ followed by $30 \%$ ACS (LAE200-ACS30) treatment reduced initial Salmonella counts on poultry carcasses by $1.8,1.4$ and $1.8 \log \mathrm{cfu} / \mathrm{mL}(\mathrm{p}<0.05)$, respectively, after 0,3 , and 6 days storage. Immediately after the treatments, EPL300-ACS30 and LAE200-ACS30 both reduced Escherichia coli counts significantly by 2.6 and $2.9 \mathrm{log} \mathrm{cfu} / \mathrm{mL}$, respectively. EPL300-ACS30 and LAE200-ASC30 were effective in lowering psychrotroph counts by 1 log cfu/mL on day 10 when compared to the control and distilled water treatments. This study demonstrated that EPL300-ACS30 and LAE200-ACS30 were effective in reducing Salmonella on inoculated chicken carcasses both after treatment and during the storage at $4.4^{\circ} \mathrm{C}$ for up to 6 days. In addition, reductions in psychrotroph counts indicated that these treatments might have the potential to increase the shelf-life of poultry carcasses. (Key Words: Salmonella, Poultry, Chicken, Storage, Decontamination, Sequential Treatments)
\end{abstract}

\section{INTRODUCTION}

In 2012, Salmonella infection was the most common infection reported (16.42 illnesses per 100,000 persons) and was associated with the largest number of hospitalizations $(2,284)$ and deaths in the United States and no significant

\footnotetext{
* Corresponding Author: Hakan Benli. Tel: +90-5068106686, E-mail: hbenli@cu.edu.tr

${ }^{1}$ Department of Food Engineering, Cukurova University, Adana 01330, Turkey.

2 Department of Animal and Food Sciences, Texas Tech University, Lubbock, TX 79409, USA.

${ }^{3}$ Department of Food Hygiene and Technology, Firat University, Elazig 23119, Turkey.

${ }^{4}$ Department of Food Technology, Universidad de Oriente, Núcleo de Nueva Esparta, Escuela de Ciencias Aplicadas del Mar, Boca del Río, 6301, Venezuela.

Submitted Sept. 11, 2014; Revised Nov. 5, 2014; Accepted Nov. 23, 2014
}

change in the incidence of Salmonella infection has occurred when compared to the 2006 through 2008 period (Centers for Disease Control and Prevention, 2013). As suggested by Centers for Disease Control and Prevention, enhanced measures are needed to further reduce pathogens and the total bacterial load on poultry carcasses. One approach is to spray carcasses sequentially with more than one decontamination agent to take advantage of their different modes of action for inactivating pathogens (Koohmaraie et al., 2005; Benli et al., 2011).

Acidic calcium sulfate (ACS) is an acidic decontamination agent and its use in the production of meat and poultry products has been approved as a secondary direct food additive by the United States Department of Agriculture Food Safety and Inspection Service (USDAFSIS) (US Department of Agriculture Food Safety and Inspection Service, 2013). $\varepsilon$-Polylysine (EPL), a natural fermentation product produced by Streptomyces albulus, is 
a homo-poly-amino acid consisting of 25 to 35 L-lysine molecules connected by a peptide bond between the carboxyl and $\varepsilon$-amino groups. The EPL has been shown to have a wide range of antimicrobial activity and is characterized as an edible, water soluble agent that is stable at high temperatures, and under acidic and alkaline conditions (Yoshida and Nagasawa, 2003; Geornaras et al., 2007). The EPL is generally recognized as safe (GRAS) by the US Food and Drug Administration as an antimicrobial agent for use in cooked or sushi rice at levels up to 50 $\mathrm{mg} / \mathrm{kg}$ rice (US Food and Drug Administration, 2004). Lauramide arginine ethyl ester (LAE), also known as lauric arginate, is an antimicrobial compound derived from lauric acid and arginine with a broad-spectrum of antimicrobial activity (Rodriguez et al., 2004; Bakal and Diaz, 2005). The LAE was also confirmed as GRAS by the USDA-FSIS and is considered a safe and suitable ingredient when used in the production of meat and poultry products (US Department of Agriculture Food Safety and Inspection Service, 2013). In a previous study, sequential spray applications of $300 \mathrm{mg}$ of EPL per liter followed by $30 \%$ ACS and of $200 \mathrm{mg}$ of LAE per liter followed by $30 \%$ ACS were found to produce the highest Salmonella reductions on inoculated chicken carcasses immediately after the treatments, by 2.1 and 2.2 $\log \mathrm{cfu} / \mathrm{mL}$, respectively (Benli et al., 2011). However, further studies were needed to determine the efficacy of these sequential spray applications of decontamination treatments during the refrigerated storage $\left(4.4^{\circ} \mathrm{C}\right)$ of the carcasses before the consumption.

Thus, the objectives of this study were to determine the effects of sequential application of EPL or LAE sprays followed by an ACS spray during 6 days of refrigerated storage on the reduction of Salmonella of inoculated chicken carcasses. Secondly, further reductions of the resident microflora on uninoculated chicken carcasses during processing steps and refrigerated storage were hypothesized. By combining these treatments, potential synergistic interactions were expected to improve antimicrobial efficacy due to the different modes of action of the individual decontamination agents.

\section{MATERIALS AND METHODS}

\section{Media}

Xylose lysine agar plates supplemented with Tergitol 4 (XLT4; Difco, Becton Dickson, Sparks, MD, USA) were poured after supplementing $20 \mathrm{mg} / \mathrm{L}$ nalidixic acid and 25 $\mathrm{mg} / \mathrm{L}$ novobiocin (Sigma, St. Louis, MO, USA) as a selective medium to enumerate nalidixic acid and novobiocin-resistant marker pathogens including Salmonella typhimurium and Salmonella enteritidis. Stock solutions of each antibiotic were prepared by dissolving 200 $\mathrm{mg}$ nalidixic acid and $250 \mathrm{mg}$ novobiocin in $10 \mathrm{~mL}$ sterile distilled water followed by filter-sterilization. Escherichia coli counts were enumerated using 3M Petrifilm E. coli/ Coliforms Count Plates (3M Microbiology, St. Paul, MN, USA). Aerobic plate counts (APC) and psychrotrophs were performed using standard plate count agar (PCA; Difco, Becton Dickson, Sparks, MD, USA).

\section{Sample collection and application of decontamination sprays}

Fresh, prerigor broiler carcasses were obtained immediately post-evisceration from a poultry processor located in Bryan, TX, USA. Eviscerated broiler carcasses were randomly collected from the processing line before entering the inside-outside bird washer and individually placed in $9.46 \mathrm{~L}$ ( 2.5 gal) HeftyOneZip bags. The bags were then placed in an insulated container and transported to the laboratory within $20 \mathrm{~min}$.

A stainless steel, custom-built spray cabinet (CHAD Corporation, Olathe, KS, USA) was used to apply decontamination sprays as previously described by Benli et al. (2011).

\section{Sequential treatments for reducing Salmonella on inoculated chicken carcasses}

Salmonella inoculum containing nalidixic acid and novobiocin resistant Salmonella enterica serovars including Salmonella typhimurium and Salmonella enteritidis as marker pathogens were prepared and inoculated on chicken carcasses as previously described by Benli et al. (2011).

Experiments were performed to determine antibioticresistant Salmonella reductions on inoculated chicken carcasses after a $20 \mathrm{~s}$ spray application of EPL or LAE followed by ACS with a $40 \mathrm{~s}$ time interval between the first and second spray. Carcasses were sampled and then stored at $4.4^{\circ} \mathrm{C}$ for up to 6 days. Sequential interventions to be evaluated included: i) $300 \mathrm{mg} / \mathrm{L}$ EPL followed by $30 \%$ ACS (EPL300-ACS30), ii) $200 \mathrm{mg} / \mathrm{L}$ LAE followed by $30 \%$ ACS (LAE200-ACS30), iii) sterile distilled water sprayed on carcasses two times, and iv) control without spray. After application of the treatments, the carcasses were randomly assigned to a 0,3 , and 6 day storage period and placed in labeled poultry rinsing bags (Nasco, Fort Atkinson, WI, USA). The bag labeled 0 day was subjected to an immediate rinse as described below while the bags labeled for 3 and 6 days were tied and held at $4.4^{\circ} \mathrm{C}$ for further analyses.

Sequential treatments for reducing aerobic plate counts, $E$. coli and psychrotrophs on uninoculated chicken carcasses

Experiments were performed to determine reductions in APC, E. coli, and psychrotrophs on uninoculated chicken carcasses. The carcasses received a $20 \mathrm{~s}$ spray of EPL or 
LAE followed by ACS after a $40 \mathrm{~s}$ time interval between first and second sprays. After transporting to the laboratory, each bagged carcass was then subjected to the appropriate intervention treatment as described above. Carcasses were randomly picked for decontamination treatments, chilling and refrigerated storage for up to 10 days. Following the spray application of the assigned treatments, carcasses were transferred into the poultry rinsing bags for an immediate rinse of buffered peptone water (BPW) as described below while the remaining carcasses were transferred into iced water to chill for $1 \mathrm{~h}$. Carcasses were then transferred into poultry rinsing bags for either an immediate rinse to perform microbiological analyses or held for up to 10 days at $4.4^{\circ} \mathrm{C}$.

\section{Sampling and microbiological analyses}

Carcasses on which microbiological analyses were to be performed were transferred into poultry rinsing bags (Nasco, Fort Atkinson, WI, USA) and $400 \mathrm{~mL}$ of sterile BPW added. The carcasses were then rinsed inside and out with a rocking motion for $1 \mathrm{~min}$ by grasping the broiler carcass in the bag with one hand and the closed top of the bag with the other hand to assure that all surfaces were rinsed (US Department of Agriculture Food Safety and Inspection Service, 2008). Following immediate serial dilutions of the rinses with sterile BPW, appropriate dilutions were used for duplicate plating of each microbiological analysis. Counts of nalidixic acid and novobiocin-resistant Salmonella typhimurium and Salmonella enteritidis were determined by plating $0.1 \mathrm{~mL}$ of appropriate diluents onto the selective XLT4 agar. The plates were incubated at $37^{\circ} \mathrm{C}$ for $24 \mathrm{~h}$ before enumeration of characteristic colonies. The nalidixic acid and novobiocin-resistant Salmonella developed black centered colonies when viewed on the XLT4 media. E. coli counts were enumerated after spread plating $1 \mathrm{~mL}$ of appropriate diluents onto $3 \mathrm{M}$ Petrifilm E. coli/Coliforms Count Plates (3M Microbiology, USA) and incubating at $37^{\circ} \mathrm{C}$ for $48 \mathrm{~h}$ according to the manufacturer's instructions. APCs were determined by plating $0.1 \mathrm{~mL}$ of appropriate diluents onto PCA and incubated at $37^{\circ} \mathrm{C}$ for $48 \mathrm{~h}$ while counts of psychrotrophs were determined after plating on PCA and incubating at $4^{\circ} \mathrm{C}$ for 10 days before enumeration.

\section{$\mathbf{L} * \mathbf{a} * \mathbf{b} *$ colorspace value}

Three readings were taken before and after Salmonella inoculation and after treatments on the external skin surface of the breast area of the chickens using a Minolta Colorimeter (CR-200, Minolta C., Ramsey, NJ, USA) (Benli et al., 2011).

\section{Statistical analyses}

The average number of colonies from duplicate plates was recorded for each sample. The results were converted to units of log colony-forming unit (CFU) per milliliter of rinse. The simple effect of treatments within each storage day was determined with analysis of variance (ANOVA) procedures for Salmonella reduction on inoculated chicken carcasses. In addition, the simple effect of treatments within each processing step was determined with ANOVA procedures for APC, E. coli, coliforms, and psychrotrophs on uninoculated chicken carcasses. Statistical analyses of data were performed with SAS 9.1 software (SAS Institute, Cary, NC, USA). All experiments were replicated three times for collecting the data. ANOVA procedures were performed using PROC general linear model procedure and Tukey multiple comparison test was used to determine the significant differences (SAS Institute Inc., 2004).

\section{RESULTS AND DISCUSSION}

\section{Salmonella reduction on inoculated chicken carcasses}

Mean counts of the marker Salmonella on control chicken carcasses and chicken carcasses sprayed with distilled water, EPL300-ACS30 or LAE200-ACS30 and stored at $4.4^{\circ} \mathrm{C}$ for up to 6 days are presented in Table 1 . The mean initial inoculation level of Salmonella was 6.2 $\log \mathrm{cfu} / \mathrm{mL}$ on the surfaces of inoculated, untreated control carcasses. There were no significant differences among Salmonella counts on control and distilled water sprayed carcasses over 6 days of storage. EPL300-ACS30 reduced Salmonella counts significantly $(\mathrm{p}<0.05)$ by 1.5 and $1.2 \mathrm{log}$ $\mathrm{cfu} / \mathrm{mL}$ on storage day 0 and 6 when compared to the control. Likewise, LAE200-ACS30, produced significantly $(p<0.05)$ lower Salmonella counts on each storage day when compared to the control with the reductions of 1.8 , 1.4 and $1.8 \log \mathrm{cfu} / \mathrm{mL}$ on 0,3 , and 6 days of storage, respectively. The results were consistent with the hypothesis that the sequential application of two decontamination agents is effective in reducing Salmonella counts on inoculated chicken carcasses due to their different mode of

Table 1. Mean counts of Salmonella including Salmonella typhimurium and Salmonella enteritidis serovars on chicken carcasses sprayed with distilled water, EPL300-ACS30 or LAE200-ACS30 and stored at $4.4^{\circ} \mathrm{C}$ for up to 6 days

\begin{tabular}{lccc}
\hline \multirow{2}{*}{ Treatment } & \multicolumn{3}{c}{ Salmonella counts \pm SD $(\log$ cfu/mL) } \\
\cline { 2 - 4 } & Day 0 & Day 3 & Day 6 \\
\hline Control & $6.2 \pm 0.0^{\mathrm{a}}$ & $6.4 \pm 0.1^{\mathrm{a}}$ & $6.3 \pm 0.1^{\mathrm{a}}$ \\
Distilled water & $6.0 \pm 0.1^{\mathrm{a}}$ & $6.1 \pm 0.2^{\mathrm{ab}}$ & $5.9 \pm 0.0^{\mathrm{ab}}$ \\
EPL300-ACS30 $^{1}$ & $4.7 \pm 0.3^{\mathrm{b}}$ & $5.2 \pm 0.6^{\mathrm{ab}}$ & $5.1 \pm 0.3^{\mathrm{bc}}$ \\
LAE200-ACS30 $^{2}$ & $4.4 \pm 0.3^{\mathrm{b}}$ & $5.0 \pm 0.4^{\mathrm{b}}$ & $4.5 \pm 0.5^{\mathrm{c}}$ \\
\hline
\end{tabular}

EPL, $\varepsilon$-polylysine; ACS, acidic calcium sulfate; LAE, lauramide arginine ethyl ester; $\mathrm{SD}$, standard deviation.

${ }^{1}$ EPL300-ACS30, EPL $300 \mathrm{mg} / \mathrm{L}$ followed by ACS 30\% solution with a $40 \mathrm{~s} \mathrm{time} \mathrm{interval.}$

${ }^{2}$ LAE200-ACS30, LAE $200 \mathrm{mg} / \mathrm{L}$ followed by ACS 30\% solution with a $40 \mathrm{~s}$ time interval.

Means in the same column with different superscript letters are significantly different $(\mathrm{p}<0.05)$. 
actions. Similar to our findings with the distilled water spray, bird washing systems with water alone have been reported not to be effective interventions for reducing attached pathogens such as Salmonella, Campylobacter, E. coli and APC or coliforms (Fletcher et al., 1997; Byrd et al., 2002; Jimenez et al., 2002; Jimenez et al., 2003; Northcutt et al., 2003; Northcutt et al., 2005). However, bird washers are effective for removing loose material from carcass surfaces during evisceration (Fletcher et al., 1997; Byrd et al., 2002; Jimenez et al., 2002). The EPL has been reported to have enhanced antimicrobial activity when combined with glycine, vinegar, ethanol and thiamine laurylsulfonate (Yoshida and Nagasawa, 2003). Njongmeta et al. (2011) also reported that spray of warm solutions $\left(55^{\circ} \mathrm{C}\right)$ of $20 \%$ ACS plus $100 \mathrm{mg} / \mathrm{L}$ EPL was effective for reducing Salmonella typhimurium, E. coli $\mathrm{O} 157: \mathrm{H} 7$, and Listeria monocytogenes on beef rounds. In addition, LAE has been shown to effectively inhibit growth of Listeria monocytogenes on cooked meats during refrigerated storage (Bakal and Diaz, 2005; Luchansky et al., 2005). In a previous study, Benli et al. (2011) determined that EPL300ACS30 and LAE200-ACS30 were the most effective treatments to reduce Salmonella counts on inoculated chicken carcasses immediately after the application of treatments. The results of the current study further demonstrated that EPL300-ACS30 and LAE200-ACS30 were not only effective immediately after the treatment but also effective during the 6 days of refrigerated $\left(4.4^{\circ} \mathrm{C}\right)$ storage for reducing Salmonella on inoculated chicken carcasses.

\section{$L^{*} a^{*} b^{*}$ color space value on inoculated chicken carcasses}

$L^{*} a^{*} b *$ (lightness, redness, yellowness, respectively) values were statistically analyzed to determine differences among "before inoculation" "after inoculation" and "after treatment" measurements for each intervention (Table 2). EPL300-ACS30 produced a significantly $(\mathrm{p}<0.05)$ lower L* value and higher $\mathrm{b}^{*}$ value after treatment. Similarly, LAE200-ACS30 caused a significantly $(p<0.05)$ lower $L^{*}$ value and higher $b^{*}$ value after treatment. A decrease in $L^{*}$ value and an increase in $b^{*}$ value on broiler skin were also reported by use of organic acids including acetic acid, citric acid, lactic acid, malic acid, mandelic acid and tartaric acids during processing steps (Bilgili et al., 1998). In this study, none of the decontamination treatments affected $a^{*}$ values of chicken carcasses regardless of the time of measurement. The color data indicated that surface of the chicken carcass became just slightly darker and more yellow after application of EPL300-ACS30 and LAE200-ACS30 treatments, and that these changes might be detected by consumers.

Aerobic plate counts, E. coli, and psychrotrophs reduction on uninoculated chicken carcasses

Aerobic plate counts of uninoculated chicken carcasses after treatment, after chilling and after storage (10 day at $4.4^{\circ} \mathrm{C}$ ) are presented in Table 3. The initial mean APC on uninoculated, control chicken carcasses was $4.7 \log \mathrm{cfu} / \mathrm{mL}$. Even though numerically lower APC were observed following the treatments of EPL300-ACS30, LAE200ACS30 with corresponding counts of 3.6 and $3.8 \mathrm{log}$ $\mathrm{cfu} / \mathrm{mL}$, respectively, they were not significantly different when compared to the control $(4.7 \log \mathrm{cfu} / \mathrm{mL})$ and distilled water treatment $(5.0 \log \mathrm{cfu} / \mathrm{mL})$. Although there were no significant differences when compared to control and distilled water treatment, EPL300-ACS30 and LAE200ACS30 treatments produced numerically lower average $\mathrm{APC}$ at the end of the storage.

The average initial count of $E$. coli on uninoculated chicken carcasses was $4.0 \mathrm{log} \mathrm{cfu} / \mathrm{mL}$ (Table 4). Distilled water treatment was not effective for reducing $E$. coli

Table 2. Mean $\mathrm{L} * \mathrm{a} * \mathrm{~b} *$ color values of chicken carcasses for before inoculation, after inoculation and after treatment sequentially sprayed with distilled water, EPL300-ACS30 or LAE200-ACS30

\begin{tabular}{|c|c|c|c|c|}
\hline \multirow{2}{*}{ Treatments } & \multirow{2}{*}{$\begin{array}{c}\text { Color measurement } \\
\text { time }\end{array}$} & \multicolumn{3}{|c|}{ Color space value } \\
\hline & & $\mathrm{L}^{*} \pm \mathrm{SD}$ & $\mathrm{a}^{*} \pm \mathrm{SD}$ & $b^{*} \pm$ SD \\
\hline \multirow[t]{3}{*}{ Distilled water } & Before inoculation & $69.51 \pm 3.08^{\mathrm{a}}$ & $0.77 \pm 1.08^{\mathrm{a}}$ & $3.82 \pm 2.70^{\mathrm{a}}$ \\
\hline & After inoculation & $68.54 \pm 3.44^{\mathrm{a}}$ & $0.83 \pm 0.81^{\mathrm{a}}$ & $3.96 \pm 2.59 \mathrm{a}$ \\
\hline & After treatment & $68.64 \pm 2.97^{\mathrm{a}}$ & $0.62 \pm 0.80^{\mathrm{a}}$ & $4.47 \pm 2.29^{\mathrm{a}}$ \\
\hline \multirow[t]{3}{*}{ EPL300-ACS30 ${ }^{1}$} & Before inoculation & $68.72 \pm 2.94^{\mathrm{a}}$ & $0.96 \pm 1.06^{\mathrm{a}}$ & $3.34 \pm 2.46^{\mathrm{b}}$ \\
\hline & After inoculation & $68.89 \pm 2.22^{\mathrm{a}}$ & $0.75 \pm 0.67^{\mathrm{a}}$ & $2.69 \pm 1.36^{\mathrm{b}}$ \\
\hline & After treatment & $66.57 \pm 2.55^{\mathrm{b}}$ & $0.89 \pm 1.71^{\mathrm{a}}$ & $5.83 \pm 2.10^{\mathrm{a}}$ \\
\hline \multirow[t]{3}{*}{ LAE200-ACS30 ${ }^{2}$} & Before inoculation & $70.35 \pm 2.21^{\mathrm{a}}$ & $0.82 \pm 1.36^{\mathrm{a}}$ & $3.43 \pm 3.08^{\mathrm{b}}$ \\
\hline & After inoculation & $68.68 \pm 2.60^{\mathrm{b}}$ & $0.61 \pm 0.88^{\mathrm{a}}$ & $3.62 \pm 2.24^{\mathrm{b}}$ \\
\hline & After treatment & $64.93 \pm 2.27^{\mathrm{c}}$ & $1.06 \pm 1.78^{\mathrm{a}}$ & $7.24 \pm 2.55^{\mathrm{a}}$ \\
\hline
\end{tabular}

EPL, $\varepsilon$-polylysine; ACS, acidic calcium sulfate; LAE, lauramide arginine ethyl ester; SD, standard deviation.

${ }^{1}$ EPL300-ACS30, EPL $300 \mathrm{mg} / \mathrm{L}$ followed by ACS $30 \%$ solution with a $40 \mathrm{~s}$ time interval

${ }^{2}$ LAE200-ACS30, LAE $200 \mathrm{mg} / \mathrm{L}$ followed by ACS 30\% solution with a $40 \mathrm{~s}$ time interval.

Means with different superscript letters are significantly different $(\mathrm{p}<0.05)$ within the same column for each treatment. 
Table 3. Mean aerobic plate counts on chicken carcasses after spray treatment with distilled water, EPL300-ACS30 or LAE200ACS30, after chilling and after 10 days of storage at $4.4^{\circ} \mathrm{C}$

\begin{tabular}{lccc}
\hline \multirow{2}{*}{ Treatments } & \multicolumn{3}{c}{ Aerobic plate counts \pm SD $(\log \mathrm{cfu} / \mathrm{mL})$} \\
\cline { 2 - 4 } & $\begin{array}{c}\text { After } \\
\text { treatment }\end{array}$ & $\begin{array}{c}\text { After } \\
\text { chilling }\end{array}$ & $\begin{array}{c}\text { After } \\
\text { storage }\end{array}$ \\
\hline Control & $4.7 \pm 0.8^{\mathrm{a}}$ & $3.7 \pm 0.3^{\mathrm{a}}$ & $5.5 \pm 0.7^{\mathrm{a}}$ \\
Distilled water & $5.0 \pm 0.2^{\mathrm{a}}$ & $3.9 \pm 0.3^{\mathrm{a}}$ & $5.4 \pm 0.6^{\mathrm{a}}$ \\
EPL300-ACS30 $^{1}$ & $3.6 \pm 0.6^{\mathrm{a}}$ & $3.7 \pm 0.4^{\mathrm{a}}$ & $4.6 \pm 0.9^{\mathrm{a}}$ \\
LAE200-ACS30 $^{2}$ & $3.8 \pm 0.2^{\mathrm{a}}$ & $4.2 \pm 0.9^{\mathrm{a}}$ & $4.0 \pm 0.4^{\mathrm{a}}$ \\
\hline
\end{tabular}

EPL, $\varepsilon$-polylysine; ACS, acidic calcium sulfate; LAE, lauramide arginine ethyl ester; SD, standard deviation.

${ }^{1}$ EPL300-ACS30, EPL $300 \mathrm{mg} / \mathrm{L}$ followed by ACS 30\% solution with a 40 s time interval.

${ }^{2}$ LAE200-ACS30, LAE $200 \mathrm{mg} / \mathrm{L}$ followed by ACS 30\% solution with a $40 \mathrm{~s}$ time interval.

Means in the same column with different superscript letters are significantly different $(\mathrm{p}<0.05)$.

counts on uninoculated chicken carcasses. Immediately after treatment, EPL300-ACS30 and LAE200-ACS30 both reduced E. coli counts significantly by 2.6 and $2.9 \mathrm{log}$ $\mathrm{cfu} / \mathrm{mL}$, respectively, compared to the control and distilled water spray. However, following chilling and storage, counts of $E$. coli were not different for any of the treatments.

The average initial psychrotroph counts on uninoculated chicken carcasses were low at $1.2 \log \mathrm{cfu} / \mathrm{mL}$ (Table 5) while distilled water treatment had a similar count of 1.5 $\log$ cfu/mL. EPL300-ACS30 and LAE200-ACS30 produced significantly $(\mathrm{p}<0.05)$ lower psychrotroph counts following chilling and storage when compared to the control and distilled water treatments. Psychrotrophs counts increased at the end of the 10 days of storage at $4.4^{\circ} \mathrm{C}$ for all treatments. Nevertheless, sequential application of EPL300-ACS30 and LAE200-ACS30 reduced psychrotroph counts more than $1 \log \mathrm{cfu} / \mathrm{mL}$ after 10 days of storage at $4.4^{\circ} \mathrm{C}$ when compared to the control and

Table 4. Mean counts of Escherichia coli on chicken carcasses after spray treatment with distilled water, EPL300-ACS30 or LAE200-ACS30, after chilling and after 10 days of storage at $4.4^{\circ} \mathrm{C}$

\begin{tabular}{lccc}
\hline \multirow{2}{*}{ Treatments } & \multicolumn{3}{c}{ Escherichia coli \pm SD $(\log$ cfu/mL) } \\
\cline { 2 - 4 } & $\begin{array}{c}\text { After } \\
\text { treatment }\end{array}$ & $\begin{array}{c}\text { After } \\
\text { chilling }\end{array}$ & $\begin{array}{c}\text { After } \\
\text { storage }\end{array}$ \\
\hline Control & $4.0 \pm 0.5^{\mathrm{a}}$ & $1.8 \pm 0.1^{\mathrm{a}}$ & $0.5 \pm 0.4^{\mathrm{a}}$ \\
Distilled water & $4.0 \pm 0.4^{\mathrm{a}}$ & $1.9 \pm 0.7^{\mathrm{a}}$ & $0.3 \pm 0.6^{\mathrm{a}}$ \\
EPL300-ACS30 $^{1}$ & $1.4 \pm 0.2^{\mathrm{b}}$ & $1.9 \pm 0.4^{\mathrm{a}}$ & $0.1 \pm 0.2^{\mathrm{a}}$ \\
LAE200-ACS30 $^{2}$ & $1.1 \pm 0.2^{\mathrm{b}}$ & $3.4 \pm 1.1^{\mathrm{a}}$ & $0.1 \pm 0.2^{\mathrm{a}}$ \\
\hline
\end{tabular}

EPL, $\varepsilon$-polylysine; ACS, acidic calcium sulfate; LAE, lauramide arginine ethyl ester; SD, standard deviation.

${ }^{1}$ EPL300-ACS30, EPL $300 \mathrm{mg} / \mathrm{L}$ followed by ACS 30\% solution with a 40 s time interval.

${ }^{2}$ LAE200-ACS30, LAE $200 \mathrm{mg} / \mathrm{L}$ followed by ACS 30\% solution with a $40 \mathrm{~s}$ time interval.

Means in the same column with different superscript letters are significantly different $(\mathrm{p}<0.05)$.
Table 5. Mean counts of psychrotrophs on chicken carcasses after spray treatment with distilled water, EPL300-ACS30 or LAE200ACS30, after chilling and after 10 days of storage at $4.4^{\circ} \mathrm{C}$

\begin{tabular}{lccc}
\hline \multirow{2}{*}{ Treatments } & \multicolumn{3}{c}{ Psychrotrophs \pm SD $(\log \mathrm{cfu} / \mathrm{mL})$} \\
\cline { 2 - 4 } & $\begin{array}{c}\text { After } \\
\text { treatment }\end{array}$ & $\begin{array}{c}\text { After } \\
\text { chilling }\end{array}$ & $\begin{array}{c}\text { After } \\
\text { storage }\end{array}$ \\
\hline Control & $1.2 \pm 0.7^{\mathrm{a}}$ & $2.0 \pm 0.1^{\mathrm{a}}$ & $>7.0^{\mathrm{a}}$ \\
Distilled water & $1.5 \pm 0.7^{\mathrm{a}}$ & $2.4 \pm 0.3^{\mathrm{a}}$ & $>7.0^{\mathrm{a}}$ \\
EPL300-ACS30 $^{1}$ & $<1.0^{\mathrm{a}}$ & $<1.0^{\mathrm{b}}$ & $5.5 \pm 0.6^{\mathrm{b}}$ \\
LAE200-ACS30 $^{2}$ & $<1.0^{\mathrm{a}}$ & $<1.0^{\mathrm{b}}$ & $5.7 \pm 0.2^{\mathrm{b}}$ \\
\hline
\end{tabular}

EPL, $\varepsilon$-polylysine; ACS, acidic calcium sulfate; LAE, lauramide arginine ethyl ester; $\mathrm{SD}$, standard deviation.

${ }^{1}$ EPL300-ACS30, EPL $300 \mathrm{mg} / \mathrm{L}$ followed by ACS 30\% solution with a 40 s time interval.

${ }^{2}$ LAE200-ACS30, LAE $200 \mathrm{mg} / \mathrm{L}$ followed by ACS 30\% solution with a $40 \mathrm{~s} \mathrm{time} \mathrm{interval.}$

Means in the same column with different superscript letters are significantly different $(\mathrm{p}<0.05)$.

distilled water treatments (Table 5). Similar to the results in this study, Dickens et al. (2004) found that spraying a higher concentration (1:1 solution of deionized water and $\mathrm{Safe}_{2} \mathrm{O}$ Poultry Wash) of ACS (4 mL/wing) increased the shelf life of chicken wings from 7 days to 10 days when compared with deionized water-spray controls. In addition, Sanchez et al. (2002) reported that counts of psychrotrophs were significantly higher for immersion chilled carcasses than air-chill carcasses $(3.20 \log$ and $1.91 \log \mathrm{cfu} / \mathrm{mL}$, respectively). The results of the psychrotroph counts indicated that both EPL300-ACS30 and LAE200-ACS30 might have a potential to reduce resident microflora on chicken carcasses during processing and storage.

Salmonella infection is the most common infection reported among the foodborne illnesses and associated with the largest number of hospitalizations and deaths in recent years. Even though the efforts for reducing the contamination rates at the chicken production stage are promising, contaminations rates still remain high and therefore endanger public health. This research demonstrates that multi-hurdle interventions applied during the processing stage as sequential decontamination sprays including EPL300-ACS30 or LAE200-ACS30 can be effectively used for pathogen reduction and possibly for increasing shelf-life of fresh poultry.

\section{CONCLUSION}

In this study, the sequential application of two decontamination agents including EPL300-ACS30 and LAE200-ACS30 were shown to be effective in reducing Salmonella on inoculated chicken carcasses not only after treatment but also during the storage at $4.4^{\circ} \mathrm{C}$ for up to 6 days. Additionally, both EPL300-ACS30 and LAE200ACS30 applications might have potential to increase the shelf-life of poultry carcasses by reducing some resident 
microflora on chicken carcasses during the processing and the storage at $4.4^{\circ} \mathrm{C}$ for up to 10 days.

\section{ACKNOWLEDGMENTS}

We extend special thanks to Dr. Irfan Ilhak, Dr. Maryuri Núñez De González, Dr. Han Yang, Dr. Carmen Gomes, Dr. Grihalakshmi Kakani, Mr. Gabriel Chemielewski as well as commercial suppliers of the decontamination agents and administration of the commercial poultry processing facility from where samples were obtained.

\section{REFERENCES}

Bakal, G. and A. Diaz. 2005. The lowdown on lauric arginate: food antimicrobial hammers away at plasma membrane, disrupting a pathogen's metabolic process. http://www.abingredients.com/ media/press/lowdown_on_lauric_arginate.html Accessed February 2, 2014.

Benli, H., M. X. Sanchez-Plata, and J. T. Keeton. 2011. Efficacy of epsilon-polylysine, lauric arginate, or acidic calcium sulfate applied sequentially for Salmonella reduction on membrane filters and chicken carcasses. J. Food Prot. 74:743-750.

Bilgili, S. F., D. E. Conner, J. L. Pinion, and K. C. Tamblyn. 1998. Broiler skin color as affected by organic acids: Influence of concentration and method of application. Poult. Sci. 77:752757.

Byrd, J. A., B. M. Hargis, D. E. Corrier, R. L. Brewer, D. J. Caldwell, R. H. Bailey, J. L. McReynolds, K. L. Herron, and L. H. Stanker. 2002. Fluorescent marker for the detection of crop and upper gastrointestinal leakage in poultry processing plants. Poult. Sci. 81:70-74.

Centers for Disease Control and Prevention. 2013. Incidence and trends of infection with pathogens transmitted commonly through food - foodborne diseases active surveillance network, 10 U.S. sites, 1996-2012. Morb. Mortal. Wkly. Rep. 62:283287.

Dickens, J. A., K. D. Ingram, and A. Hinton. 2004. Effects of applying $\mathrm{Safe}_{2} \mathrm{O}$ poultry wash to broiler wings on shelf life, Listeria monocytogenes, Pseudomonads, Staphylococcus species, and psychrotrophic bacteria levels after three, seven, and ten days of storage. Poult. Sci. 83:1047-1050.

Fletcher, D. L., E. W. Craig, and J. W. Arnold. 1997. An evaluation of on-line "reprocessing" on visual contamination and microbiological quality of broilers. J. Appl. Poult. Res. 6:436442.

Geornaras, I., Y. Yoon, K. E. Belk, G. C. Smith, and J. N. Sofos. 2007. Antimicrobial activity of $\varepsilon$-polylysine against Escherichia coli O157:H7, Salmonella typhimurium, and Listeria monocytogenes in various food extracts. J. Food Sci. 72:M330-334.

Jimenez, S. M., M. S. Salsi, M. C. Tiburzi, and M. E. Pirovani. 2002. A comparison between broiler chicken carcasses with and without visible faecal contamination during the slaughtering process on hazard identification of Salmonella spp. J. Appl. Microbiol. 93:593-598.
Jimenez, S. M., M. C. Tiburzi, M. S. Salsi, M. E. Pirovani, and M. A. Moguilevsky. 2003. The role of visible faecal material as a vehicle for generic Escherichia coli, coliform, and other enterobacteria contaminating poultry carcasses during slaughtering. J. Appl. Microbiol. 95:451-456.

Koohmaraie, M., T. M. Arthur, J. M. Bosilevac, M. Guerini, S. D. Shackelford, and T. L. Wheeler. 2005. Post-harvest interventions to reduce/eliminate pathogens in beef. Meat Sci. 71:79-91.

Luchansky, J. B., J. E. Call, B. Hristova, L. Rumery, L. Yoder, and A. Oser. 2005. Viability of Listeria monocytogenes on commercially-prepared hams surface treated with acidic calcium sulfate and lauric arginate and stored at $4{ }^{\circ} \mathrm{C}$. Meat Sci. 71:92-99.

Njongmeta, N. L. A., H. Benli, K. D. Dunkley, C. S. Dunkley, D. R. Miller, R. C. Anderson, C. A. O'Bryan, J. T. Keeton, D. J. Nisbet, P. G. Crandall, and S. C. Ricke. 2011. Application of acidic calcium sulfate and $\varepsilon$-polylysine to pre-rigor beef rounds for reduction of pathogens. J. Food Saf. 31:395-400.

Northcutt, J. K., M. E. Berrang, D. P. Smith, and D. R. Jones. 2003. Effect of commercial bird washers on broiler carcass microbiological characteristics. J. Appl. Poult. Res. 12:435438 .

Northcutt, J. K., D. P. Smith, M. T. Musgrove, K. D. Ingram, and A. Hinton. 2005. Microbiological impact of spray washing broiler carcasses using different chlorine concentrations and water temperatures. Poult. Sci. 84:1648-1652.

Rodriguez, E., J. Seguer, X. Rocabayera, and A. Manresa. 2004. Cellular effects of monohydrochloride of L-arginine, N-lauroyl ethylester (LAE) on exposure to Salmonella typhimurium and Staphylococcus aureus. J. Appl. Microbiol. 96:903-912.

Sanchez, M. X., W. M. Fluckey, M. M. Brashears, and S. R. McKee. 2002. Microbial profile and antibiotic susceptibility of Campylobacter spp. and Salmonella spp. in broilers processed in air-chilled and immersion-chilled environments. J. Food Prot. 65:948-956.

SAS Institute Inc. 2004. SAS/STAT User's Guide, version 9.1 SAS Institute Inc., Cary, NC, USA.

U.S. Department of Agriculture Food Safety and Inspection Service. 2008. Microbiology laboratory guidebook, chap. 4.04. Isolation and identification of Salmonella from meat, poultry, and egg products. Available at: http://www.fsis.usda.gov/PDF/MLG_4_04.pdf Accessed October 5, 2009

U.S. Department of Agriculture Food Safety and Inspection Service. 2013. Safe and suitable ingredients used in the production of meat and poultry, and egg products. Available at: http://www.fsis.usda.gov/wps/wcm/connect/bab10e09-aefa483b-8be8-809a1f051d4c/7120.1.pdf?MOD=AJPERES Accessed September 20, 2013

U.S. Food and Drug Administration. 2004. Agency response letter GRAS notice no. GRN 000135. Available at: http://www.fda.gov/food/ingredientspackaginglabeling/gras/no ticeinventory/ucm153957.htm Accessed September 10, 2014

Yoshida, T. and T. Nagasawa. 2003. E-Poly-L-lysine: Microbial production, biodegradation and application potential. Appl. Microbiol. Biotechnol. 62:21-26. 